\title{
A Multimodal Discourse Analysis of Childish Gambino's Music Video "This is America”
}

\author{
María Fernanda Castillo Acosta \\ University of Guanajuato, Division of Social Sciences and Humanities
}

Received 27 September 2018 - Revised 25 November 2018 • Accepted 30 November 2018

\begin{abstract}
The portrayal of African Americans in the United States has been approached throughout the years in different fields. Childish Gambino's song and music video "This is America" offers an interesting view regarding gun control in the United States, African American stereotypes and their representation in mass media. In order to propose an interpretation of Gambino's lyrics and video, I provide a multimodal discourse analysis using the visual semiotic framework (Machin, 2010) and the systemic functional linguistics (Halliday, 1978). The findings highlight the manipulated discourse that is present in the media regarding not only African Americans but other minority groups. This "new racism" (Littlefield, 2008) has an impact on the audience, which in turn perpetuates the negative ideas and stereotypes of the African American community.
\end{abstract}

Keywords: multimodal discourse analysis, African American.

\section{Introduction}

This study serves as a multimodal discourse analysis of the lyrics and music video "This is America". The song of the video was written by Ludwig Göransson, and Childish Gambino, stage name of the musician and actor Donald Glover. The music video was directed by JapaneseAmerican director Hiro Murai. In order to approach the analysis, I will use Machin's (2010) Visual Semiotic Framework concerning the music video. For the lyrics, the components of the Systemic Functional Linguistics (SFL) proposed by Halliday (1978), will serve as a referent. I will now proceed to offer the key aspects of the literature that support the discourse regarding the AfricanAmerican culture.

\subsection{African-American discourse in the United States}

The African American culture has always been present in the mass media discourse in the United States. However, it is precisely the way that has been depicted the main focus of Childish Gambino's music video. Cartier (2014) considers that African-American culture has highly impacted the United States' pop culture, considering the presence of music genres such as hip-hop, jazz, and R\&B. However, Carter (2014: 150) discusses the dichotomy of being black: "it is always cool to possess the vitality, originality, and magnetism black people as a whole seem to imbue, while accepting none of the pain, prejudice, and struggle the fact of actually having so much

(C) Authors. Terms and conditions of Creative Commons Attribution 4.0 International (CC BY 4.0) apply. Correspondence: María Fernanda Castillo Acosta, Lucio Marmolejo \#1071, Colonia Prolongación de la Moderna, Irapuato, Guanajuato, MEXICO. E-mail: mari_fer1987@hotmaill.com. 
discernible melanin entails". It would seem that the perception of black people in terms of "how cool" they are can easily be changed.

- Representations of minority groups in mass media can have a negative impact by perpetuating stereotypes.

- Through his music, Childish Gambino offers a powerful criticism of the current situation of the African Americans in the United States, which can be interpreted through a multimodal discourse analysis.

- Different elements of the African American community have been accepted and celebrated, while others have been rejected and associated with violence and crime.

Littlefield (2008) considers that apparently the American society embraces minorities based on the representation of its communities in mass media, the efforts of the government and multiculturalism that the United States offers. However, Littlefield (2008: 676) defines these situations as "new racism", which assumes that the social changes that took effect during the civil rights movement benefited African Americans and that, consequently, America has lived up to its promise of equality. Current strategies that highlight diversity initiatives but do not single out problems faced by Black Americans dilute the real issues and needs of African Americans.

Therefore, the idea of a multicultural American society based on the equal representation of all its members might not be what it is expected. After decades of the struggle of different social movements, it seems that the concern is now focus on the ways that minorities are portray.

\subsection{African-American's identity}

It is necessary to comprehend the historical implications that have shaped the AfricanAmerican identity. Eyerman (2011: 16-17) discusses its conflicted nature by stressing that, unfortunately, slavery plays an important role in both individual and the collective understanding of who they are:

It was slavery, whether or not one had experienced it, that defined one's identity as an African American, it was why you, an African, were here, in America. It was within this identity that direct experience, the identification "former slave" or "daughter of slaves" became functionalized and made generally available as a collective and common memory to unite all blacks in the United States.

Although the variable of freedom has entered the equation, the effects of the situation in which most of the ancestors of many African Americans were brought into this continent still has an effect nowadays.

In this regard, Morgan (2002: 12) notes that the nature of this type of first contact situations "is not only to describe historical circumstances, but to contest the notions that the only way to describe African American culture is a problem -through the interpretation and supposed benevolence of the oppressors, intermediaries and onlookers and their descendants". Therefore, living in the same context as their former oppressors has had particular consequences not only in the way that African Americans perceive themselves but most importantly how they are portrayed to the rest of the world.

Brown and Kopano (2014: 3) point out that "colonial masters are committed to preserving a role for colonized people as dominated, controlled, and exploited subjects". Even though the authors recognize the influence that the African American culture has had in the popular culture, they further argue how often the media reaffirms white supremacy by conveniently using and controlling the cultural value of African Americans. 


\subsection{African-American's portrayal in mass media}

Fujioka (2005: 451) points out the ethnic identity, which is "a group-based identity formed and developed through a variety of socialization processes, including both personal experiences [...] and mediated experiences". In the latter, individuals are less likely to control the effect that their portrayals have on a society. Regarding the language, Morgan (2010: 251) discusses the African American linguistic variation. She mentions that Americans tend to "both criticize and fetishize the culture and language. The concrete result of this dualism is a dominant culture which describes African-American speech as bad, uneducated, unintelligible etc., while wantonly imitating and celebrating its wit, creative vitality, and resilience". These aspects support the previously discussed idea of the instability that African Americans have faced for many years.

Allen (2001) claims that in the case of "African Americans, mainstream media as well as the Black-oriented (ethnic) media serve as one of the influential sources of information about in-group through which African American concepts and identity are developed and negotiated" (as cited Fujioka, 2005: 451). Frequently, there have been accusations of reinforcing stereotypes of even cultural appropriation especially regarding minorities in the United States. Yet, Ghandnoosh (2010: 1581) comments how the response of white individuals towards the representations of African Americans have changed over time: "these include shifts from parodies of African Americans, to race-based segregation of musical genres, to repackaging styles developed by African Americans for white performers, to mass marketing black artists to white audiences". Moreover, it is mainly the latter, the one that has been widely recognized, slowly becoming a quite profitable industry.

Hirschman (1993) points out that "in societies such as the United States, which are characterized by unequal cultural power, ideology is one means by which dominant groups (e.g., whites, men) sustain and legitimate their power over other groups (e.g., African-Americans, Hispanics, women)" (as cited in Bristor, Gravois \& Hunt, 1995: 48). Furthermore, Bristor Gravois and Hunt (1995) highlight that the portrayal of minorities is more likely to reveal more about the Americans. In this sense, Punyanunt-Carter (2008: 241) considers that "although the quantity of African American images on television has increased, the quality of these images has not". This idea would confirm that in reality, there has not been much progress in the last decades regarding racism, except for the acceptance and popularization of certain aspects of the African American culture.

Stereotype theories claim that these ideas may be encouraged "by consistently seeing out-group members in stereotypical roles on television over a long period of time" (Dixon \& Linz, 2000: 132). This represents an issue when a crime is usually attributed to individuals that fit certain stereotypes, mostly African Americans and Latinos. Dixon and Linz (2000: 132) consider that "if the perpetrators of crime on television news are largely people of color and guardians of law usually white, then viewers of news programs may conclude that people of color are evildoers who must be subdued". Therefore, we encounter this dichotomy, where these stereotypes might result convenient when it comes to the pop culture industry, yet they are also used to continue to perpetuate wrong ideas. Dixon and Linz (2000: 4) conclude that this control of mass-mediated images results in "the subjugation of the masses, amplifying black self-degradation, and profiting financially from the media production". All three aspects were discussed throughout this section concerning of the post-slavery situation, the construction of the African American identity and the profit yet stigmatization of the stereotypes in the pop culture and mass media.

I have outlined the theoretical analysis of the most relevant aspects regarding the framework that was used to approach the framework and the African American discourse that serves as the focus of the video and lyrics. I will now proceed with the methodology that frames the analysis. 


\section{Methodology}

The approach that the present paper intends is based on the "Three-dimensional method of discourse analysis" of Fairclough (2013). In the same, a three-level analysis is provided: the text, which includes its description and analysis; its process of production and interpretation; and finally, the social explanation regarding the issue that is addressed in the source. I will offer a general over of the elements that support the three levels, in order to provide the concluding remarks concerning the social implications that the video highlights. I will start by exploring the literature of Critical Discourse Analysis.

\subsection{Critical discourse analysis}

Critical Discourse Analysis (CDA) originated in the 80's based on the work of Fairclough, van Dijk, Wodak and others (Van Leeuwen, 2015). According to Fairclough and Wodak (1997), CDA is concerned with language as a social practice, considering as crucial the context where the language is used, and taking an interest the relation between language and power (Wodak, 2001). Similarly, Leeuwen (2015: 1) claims that CDA "studies the role of text and talk in creating, maintaining, and legitimating inequality, injustice, and oppression in society. It uses discourse analysis as an empirical and rational foundation for doing so". Therefore, in order to provide a proper analysis, both ideas suggest the need for understanding the context where it was created. In this sense, Wodak (2001: 2) points out that CDA "aims to investigate critically social inequality as it is expressed, signaled, constituted, legitimized and so on by language use (or in discourse)". Furthermore, Wodak (2001) states that the current study research of CDA is heavily focused on institutional, political, gender and media discourses since such topics are conflicted continuously by precisely the issues that CDA aims to address.

Wodak (2001) highlights the concept of power, history, and ideology, as key elements in every critical discourse analysis. Wodak (2001: 3) continues stating that since every discourse is produced and interpreted in a specific time and place in history, the dominance variable plays an important role: "CDA makes it possible to analyse pressures from above and possibilities of resistance to unequal power relationships that appear as societal conventions". Therefore, many of the texts can be seen as an act of creative resistance (Fairclough \& Kress, 1993). As previously stated, different social and political factors surrounding the creation of a text need to be taken into consideration, since its creator might not only use to merely communicate or describe a circumstance but as a conduit to express an opinion and offer a critique regarding a given matter.

However, in recent years the communication has expanded beyond the written and spoken discourse. Therefore, in order to provide a systematic process to analyze any way of conveying an idea, the multimodal discourse analysis was developed.

\subsection{Multimodal discourse analysis}

According to Chan (2013: 70), multimodal discourse refers to "the study of the various methods used by humans to communicate (the discourse) including using voice, writing and 'body language' (the multimodalities)". This model proposes to offer a valid analysis of new ways of communication that have slowly gained notoriety based on technology, art and other ways of expression. In this regard, O'Halloran (2011: 120) consider that Multimodal Discourse Analysis (MDA "extends the study of language per se to the study of language in combination with other resources, such as images, scientific symbolism, gesture, action, music and sound". In this sense, any resource that is conceived to convey meaning can be properly examined.

O'Halloran (2011: 123) notes how this type of analysis gained popularity in the mid2000 s based on the increasing interest of different scholars to explore language in other resources 
beyond the written and spoken discourse: "there was an explicit acknowledgment that communication is inherently multimodal, and that literacy is not confined to language".

Regarding the semiotic analysis in music, Machin (2010: 3) states that "in the way that a linguistic might document the linguistic resources and structures available to create meaning in linguistic communication, we look for the kinds of semiotic resources and patterns available for communication in the sounds, images and worlds of popular music". Therefore, it is possible to transfer the seminal work that many scholars have developed regarding CDA and MDA in order to provide an analysis of other forms of communication.

O’Halloran (2011) maintains that Halliday's (1978) approach supports the idea that the reality of culture is embedded with semiotic resources which can be sorted as systems of meanings. Therefore, the medium such as a newspaper, a television or a computer is only "the means through which the multimodal phenomena materialize" (O'Halloran, 2011: 121). Thus, finding the right approach, or a combination of several frameworks, it is possible to create a set of different elements that are adequate to explore any given semiotic resource. If needed, as in the case of the current analysis, Halliday's Systemic Functional Linguistics (SFL) can be used in a source that provides a written form of discourse. Van Leeuwen (2015: 1) mentions that Halliday's grammar is based on "the principle that language simultaneously constructs representations of the world, realizes social interactions, and marshals these representations and interactions into texts and communicative events". The following section provides a discussion of Halliday's Systemic Functional Linguistics that will serve as the basis to approach the lyrics of the music video "This is America”.

\subsection{Halliday's systemic functional linguistics}

Haratyan (2011) establishes that in Halliday's Systemic Functional Linguistics (SFL) language as a social phenomenon is functional since it is based on the text structure, function and meaning of language. Wang (2010) notes how SFL is often regarded as the key foundation of Critical Discourse Analysis as well as other theories in pragmatics.

Haratyan (2011) begins an analysis of language in the social context where a particular lexico-grammatical choice is constructed under the influence of the social and cultural context. Meaning, central to SFL, is achieved through the linguistic choices in paradigmatic and the syntagmatic levels of discourse where the words are arranged in a clause or text. Its precursor comments that:

Discourse is a multidimensional process and text as its product not only embodies the same kind of polyphonic structuring as is found in grammar [...] but also since it is functioning at a higher level of the code, as the realization of semiotic orders above' language, may contain in itself all the inconsistencies, contradictions and conflicts that can exist within and between such high order semiotic systems (Halliday, 1978: 96).

The functions that Halliday (1978, according to Haratyan, 2011) proposes, are intended to represent the abstract metafunctions across languages:

- The ideational function is concerned with the experiential and the logical content of the text which provides an understanding of our experience of the world. It includes the concept of "transitivity" and "voice. The transitivity system includes the material process, the mental process, the relational process, the behavioral process, the verbal process, and the existential process.

- The textual function, regarding the cohesion and coherence of the text. These aspects are achieved through referencing (homophoric, exophoric, and endophoric categories); the substitution and ellipsis (to avoid the repetition using grammatical resources of the language); the use of conjunctions (to elaboration, extend or 
enhance an idea). All these elements are combined in order to achieve the lexical cohesion of a text.

- The interpersonal function, meaning the social and power relations that a text conveys, through modality or indicative or imperative clauses.

The presence of these elements was determined through the analysis of the lyrics of the song. A detailed discussion is offered in the Analysis and Discussion chapter. I will now continue with the conceptual review of the approach that was used for the analysis of the music video in order to determine other relevant connotators.

\subsection{Visual semiotic analysis}

First of all, O'Halloran (2011: 130) suggests that “the multimodal analysis includes the interactions between the spoken language, kinetic features (including gaze, body posture and gesture) and cinematography effects (including camera angle and frame size)”. Based on these aspects and due to the nature of the music video that this paper presents, the framework offered by Machin (2010) will be used.

Machin (2010: 3) proposes that "in the way that a linguistic might document the linguistic resources and structures available to create meaning in linguistic communication, we look for the kinds of semiotic resources and patterns available for communication in the sounds, images and worlds of popular music.

As previously established by Halliday, the music video of this paper serves as the semiotic resource of this analysis, which based on the current political and cultural context contains relevant meanings that can be examined. Machin (2010) recognized the work of Barthes $(1973,1977)$ and Halliday (1978) as the main source for this approach, where many of the aspects of their theory were adapted to be used in other sources of discourse. Understanding the idea that images can both denote and connote Machin (2010: 36) points out that:

- The more abstract the image, the more overt and foregrounded its connotative communicate purpose.

- Whether the communicative purpose of an image is primarily denotative or connotative depends to some extent on the context in which the image is used.

- What an image connotes may, in some contexts, be a matter of free association.

Machin (2010) considers the following aspects as the connotators that need to be taken into consideration when an analyzing an image:

- Pose, in which these questions can provide a useful insight: to what extent do artists take up space or not? do they perform for the viewer or are they selfcontained? Is there an emphasis on relaxation or intensity? to what extent do band members mirror each other or appear as individuals? Are they depicted as being intimate, standing in close proximity or is there some indication of distance? (Machin, 2010: 39)

- Gaze, which is based on Halliday's (1985) argument related to the focus of spoken discourse: offer services or goods, demand goods and services, demand information, offer information. According to Kress and van Leeuwen (1996), the two last aspects can be identified in an image. Machin (2010) suggests that a 'demanding image' would suggest the viewer is being acknowledged. On the other hand, an 'offering image' might not have the same result. It is important to take into consideration that in Western culture up and down have could provide a meaning.

- Social distance, regarding the shots. A closer or a longer shot might indicate personal or impersonal situations respectively. Jewitt and Oyama (2001) also consider that a viewing position can have meaning potential looking up could carry power connotations, while looking down could signify giving away power.

- Objects and how they are represented. 
- Settings, which can connote values, identities, and actions.

- Salience, which is concerned with features that are highlighted such as cultural symbols, size, color, tone, focus, foreground, and overlapping.

- Modality, which is based on modal auxiliaries using a scale of may (probable) to must (certain). Aspects such as the degree of the articulation of detail, background, depth, light and shadow, tone, color modulation, color saturation, and color differentiation are measured from maximum to minimum articulation of detail.

The elements of pose, gaze, social distance, objects and salience will be examined in the Analysis and Discussion section, where Machin's approach will frame the analysis of the music video. I will now proceed to review some relevant aspects of the social elements that the video addresses regarding the African American discourse in the United States.

\section{Discussion of findings}

\subsection{Analysis of the lyrics}

This section is concerned with the analysis of the lyrics of the music video This is America, by Childish Gambino. I used the Systemic Functional Linguistics proposed by Halliday (1978) to provide a grammatical analysis using the three metafunctions. Table 3 shows the analysis of the Interpersonal metafunctions, which categorize the declarative and the imperative mood.

Table 1. Interpersonal metafunctions

\begin{tabular}{|c|l|}
\hline \multirow{2}{*}{ Declarative } & $\begin{array}{l}\text { wanna / want,know/ got, dancin'/ is/ don't catch/ slipplin' } \\
\text { up/ whippin up/ 'm living/ got/ gotta carry/ 'ma go/'ma go } \\
\text { get/ get/ 'm/ gon' blow'/ told/ 'm geekin' out/ 'm gon' get/ } \\
\text { move/ gonna find/ checked/ owe }\end{array}$ \\
\hline Imperative & $\begin{array}{l}\text { go away/ dance/ shake/ tell/ go/ get/ watch/ know/ go tell/ } \\
\text { get down }\end{array}$ \\
\hline
\end{tabular}

There are no interrogative clauses throughout the song. The lyrics navigate between the imperative clauses that represent the $29.41 \%$, and the declarative which are the $70.58 \%$. Therefore, the role that Gambino establishes with the interlocutor is of indicator or presenter of information. However, there is still a significant presence of demanding, which not only means that the social distance decreases, but that would put Gambino in a different position regarding power. Table 4 is concerned with the ideational metafunctions.

Table 2. Ideational functions

\begin{tabular}{|c|c|}
\hline & go, go away \\
you got me dancin' \\
Dance and shake the frame \\
I got the strap \\
I gotta carry 'em \\
I'ma go into this \\
I'ma go get the bag \\
Material process & I'ma get the pad \\
& Get your money, black man \\
I'm gon' get it \\
I got the plug on Oaxaca \\
They gonna find you that blocka \\
One, two, get down \\
Drivin' expensive foreigns \\
\hline Behavioral process & I kenneled him in the backyard \\
\hline Mental process & - \\
\hline
\end{tabular}


M. F. Castillo Acosta - A Multimodal Discourse Analysis of Childish Gambino’s Music...

\begin{tabular}{|c|c|}
\hline & $\begin{array}{c}\text { We just want the money } \\
\text { I know you wanna party } \\
\text { Police be trippin' now } \\
\text { We gon' blow like yeah (straight up, uh) } \\
\text { Look how I'm geekin' out } \\
\text { Ooh, } \underline{\text { know that }} \\
\text { Get it } \\
\text { Ooh, work it } \\
\text { America, I just checked my following list and } \\
\text { You mothaf***as owe me }\end{array}$ \\
\hline Verbal process & $\begin{array}{l}\text { Ooh-ooh-ooh-ooh-ooh, tell somebody } \\
\text { Grandma told me }\end{array}$ \\
\hline Relational process & $\begin{array}{c}\text { Yeah, yeah, I'm so cold like yeah } \\
\text { I'm so dope like yeah } \\
\text { I'm so fitted (I'm so fitted, woo) } \\
\text { I'm on Gucci (I'm on Gucci) } \\
\text { I'm so pretty } \\
\text { That's a tool }\end{array}$ \\
\hline Existential process & $\begin{array}{c}\text { This is America } \\
\text { Yeah, yeah, this is guerilla } \\
\text { No probably ain't life to a dog }\end{array}$ \\
\hline *Material / Mental & $\begin{array}{l}\text { Don't catch (material) you slippin' up (mental) } \\
\text { Look (mental) what I'm whippin' up (material) }\end{array}$ \\
\hline${ }^{*}$ Material / Verbal & You go (material) tell (verbal) somebody \\
\hline
\end{tabular}

There is no presence of the behavioral process, which shows the lack of physiological and psychological behavior where no outcome is expected. Since this process usually requires one participant, it can be stated that Gambino expects from the interlocutor a higher participation, at least as the receiver of the information as the interpersonal metafiction suggests. On the other hand, the material process represents the $38.46 \%$, the mental process the $28.20 \%$, the verbal process the $5.12 \%$, the relational process the $15.38 \%$, and the existential process the 7.69 . Both the material and mental process have the highest percentages, which suggest the presence of action and the perception or at least the cognitive reaction of a certain phenomenon. It is relevant to mention that within a sentence both material and mental process are repeated throughout the text a considerable amount of times: Don't catch you slippin' up and Look what I'm whippin' up, which can outline the phenomenon that Gambino perceives and the immediate call for action. There is also the link between the material and verbal process with the sentence You go tell somebody, which is repeated three times, which could imply the need to communicate the phenomenon in question. I will now proceed to outline the textual functions that were identified in the lyrics.

Table 3. Textual metafunctions

\begin{tabular}{|c|c|}
\hline & Police be trippin' now \\
I got the strap \\
Yeah, yeah, this is guerilla \\
Yeah, yeah, or I'ma get the pad \\
I'm so dope like yeah \\
Look how I'm geekin' out \\
I'm on Gucci \\
This a celly \\
Referencing \\
Hunnid bands \\
I got the plug on oaxaca \\
They gonna find you that blocka \\
America, I just checked my following list \\
You just a barcode \\
Drivin' expensive foreigns
\end{tabular}




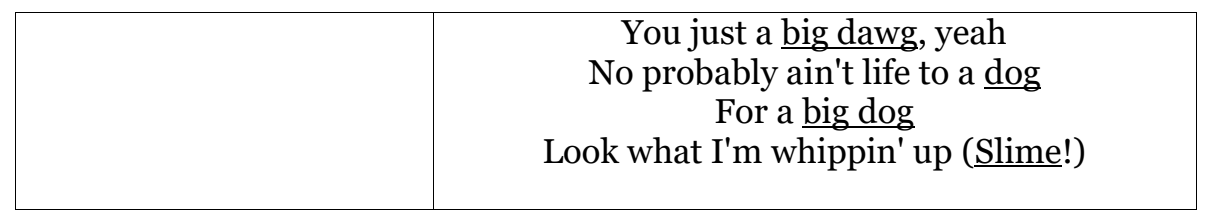

The textual functions that were present thought the song include the exophoric reference. This suggests that Gambino heavily relies on what he assumes is shared knowledge among the listeners. Most of these references are within the African American variation of English such as strap, dope, geeking out, blocka, and big dwag. Yet, there are others such as Gucci and following list, which has to do with fashion knowledge and social media respectively. Surprisingly, there is one reference to Mexico (Oaxaca), when Gambino establishes a connection with what is assumed a Mexican drug dealer, issue that it is also mentioned through other exophoric references such as guerrilla, pad, and humid bands. Therefore, Gambino is strongly establishing a referential relationship between the African American culture and drugs.

In order to complement the information provided by Halliday's (1978) Systemic Functional Linguistics, I will now examine the participants based on the Van Leewen's (1996) inventory of the ways in which participants can be represented linguistically (Machon, 2010).

Table 4. Participants in the lyrics

\begin{tabular}{|c|c|}
\hline $\begin{array}{l}\text { Personalized/ } \\
\text { impersonalized }\end{array}$ & 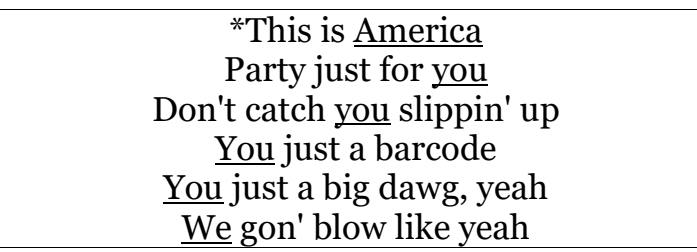 \\
\hline $\begin{array}{l}\text { Individualized/ } \\
\text { collectivized }\end{array}$ & $\begin{array}{c}\text { *This is America } \\
\text { Get your money, black man } \\
\text { America, I just checked my following list and } \\
\text { You just a black man in this world }\end{array}$ \\
\hline Nominalized & 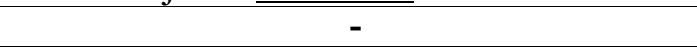 \\
\hline Functionalized & $\begin{array}{l}\text { Police be trippin' now } \\
\text { Grandma told me }\end{array}$ \\
\hline Anonymous & $\begin{array}{l}\text { Ooh-ooh-ooh-ooh-ooh tell somebody } \\
\text { Look what I'm whippin' up (Slime!) } \\
\text { You go tell somebody } \\
\text { You mothaf***as owe me } \\
\text { I kenneled him in the backyard } \\
\text { Girl, you got me dancin' }\end{array}$ \\
\hline Aggregated & ${ }^{*}$ We gon' blow like yeah \\
\hline Objectivated & Dance and shake the frame \\
\hline
\end{tabular}

The different actors and their importance in the lyrics have been established using the categories shown in Table 6. It can be established that Gambino uses anonymity and personalization, through the use of pronouns and participants that are loosely present such as girl and somebody. This can provide the interlocutors with a sense of social distance. Gambino does not name these actors, which is supported by the lack of participants in the nominalized category; or as I suggest, a deeper connection since you or somebody could really be anyone, including yourself. It can be assumed that this decision might be a strategy, in which Gambino is also addressing the depersonalization and dehumanization that gun violence has in the United States. When a tragedy occurs, the individuals of the society seems involved and concerned with the issue. Yet, as long as it is not yourself, or someone you personally know, there is the possibility of carrying on with your life. Therefore, people usually operate within this safe frame, a phenomenon that Gambino takes issue throughout the lyrics and music video. The only actors that are openly named 
are America and black man. By naming them, Gambino ensures that the message is conveyed, by setting the context where the phenomenon that he addresses takes places and identifying at least one of the most important groups that have endured it: African Americans. There is also the presence of the grandmother figure, which is mentioned three times. It can be stated that it represents a figure of trust and support since grandma is the one in the lyrics that advises the black man to get his money.

I have proved an in-depth analysis of the lyrics of the video. I have identified the grammatical aspects and the actors that support the meaning that Gambino connotes and sometimes denotes in his song. I will now continue with the analysis of the most relevant aspects of the music video "This is America".

\subsection{Visual semiotic analysis of the music video}

Using Machin's (2010) suggested connotators for the analysis of music, images, and sound, I will provide a description of the most relevant aspects, including frames from the music video that exemplified the statements.

\subsubsection{Pose}

Apart from the dancing moves throughout the music video, there are three different poses that stand out. The first one is precisely the pose in which Gambino is introduced in the video (Image 1).

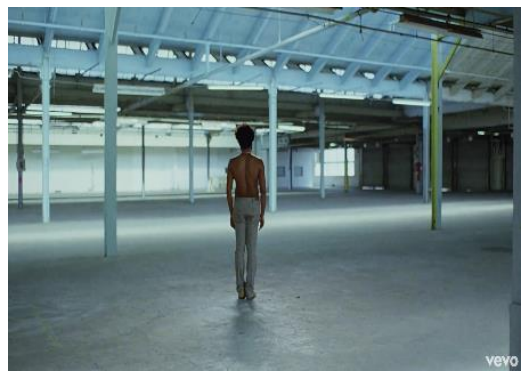

Image 1. Gambino's introductory pose (Source: Childish Gambino’s “This is America”)

Gambino is shown facing away from the camera, full body shot, in a straight position with both arms on the sides. He does not convey a relaxed state, but as if he was waiting for something. Other frames have similar poses, yet there is one in particular where he is holding a gun, as shown in Image 2.

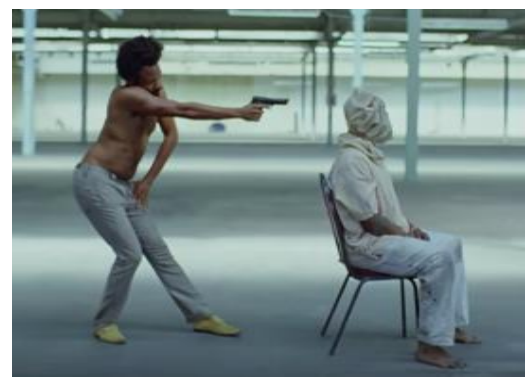

Image 2. Gambino's resemblance to Jim Crow (Source: Childish Gambino's “This is America” 
The pose might be stressed, referencing the conflicted character of Jim Crow. This could be a statement regarding the multiple stereotypes that have been used to represent African Americans.

\subsubsection{Gaze}

The video is characterized by the exaggerated facial expressions of Gambino, that fluctuate from cheerful (when dancing), to annoyed (when holding a gun or shooting). However, he always acknowledges the viewer by looking directly to the camera.

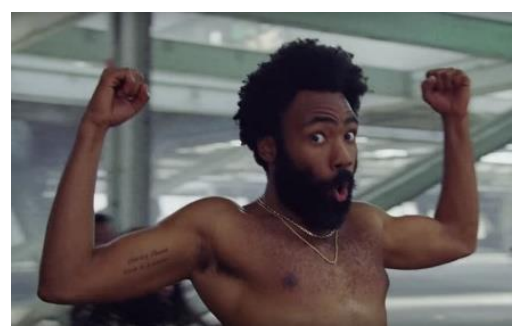

Image 3. Gambino’s facial expression (Source: Childish Gambino’s “This is America”)

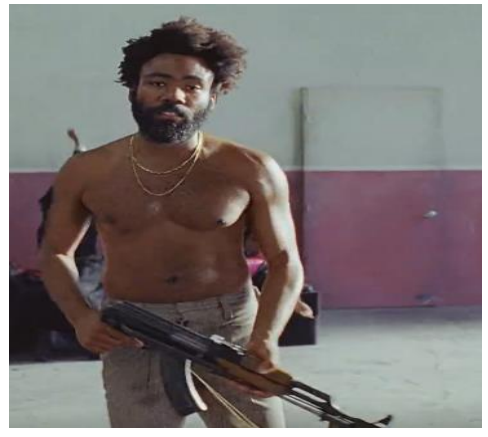

Image 4. Gambino's facial expression (Source: Childish Gambino's “This is America”)

There is one particular shot where the camera faces up, showing children who are on their cellphones capturing what is happening. Since the children are looking down, it can be stated that they are in a higher social position, since they are witnessing from a safe place what occurs with Gambino.

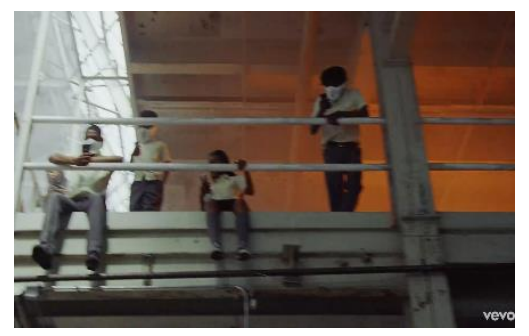

Image 5. Camera facing up (Source: Childish Gambino’s “This is America”)

\subsubsection{Social distance}

Throughout the video, the camera offers long, medium and close shots. However, the latter is more present, creating a sense of intimacy. 


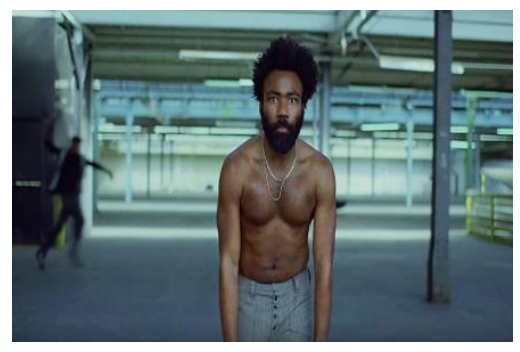

Image 6. Medium shot (Source: Childish Gambino's “This is America”)

The longer or medium shots are present to highlight the chaos in which the video develops, poses as previously discussed, or certain objects that will be addressed next. Moreover, some of the medium and long shots are reserved for some of the most relevant moments of the video.

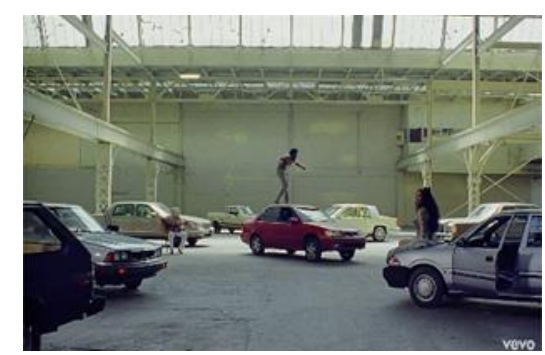

Image 7. Long shot (Source: Childish Gambino's "This is America”

The body language and dance moves of Gambino and his dancers are meant to serve as a distraction, in order to reinforce one of the key points that Gambino addresses, which is the idealization of the African American pop culture while deflecting the attention from the violence related to gun control and other important issues.

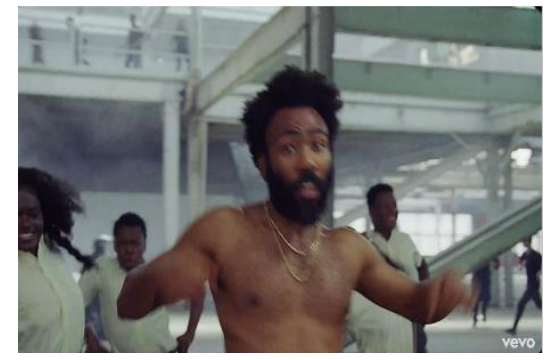

Image 8. Gambino and dancers (Source: Childish Gambino’s “This is America”)

\subsubsection{Objects}

Some of the relevant objects that are featured in the video that will be discuss are guns, which appeared twice, the double chained around Gambino's neck, and old cars which Gambino climbs on to dance. After being used, the guns are carefully wrapped using a red cloth, which can be understood as the lack of action of the American government to change the policies concerning gun control, regardless the loss of human lives. 


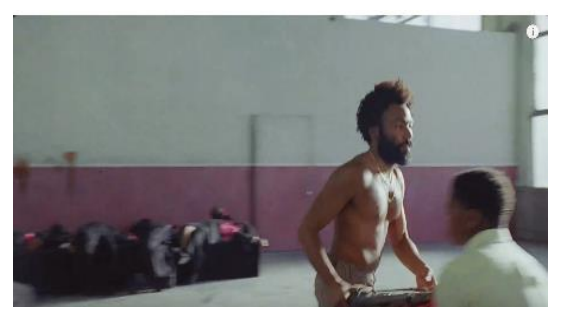

Image 9. Gambino carefully handing the gun (Source: Childish Gambino's "This is America”)

Based on the identity aspects regarding the impact of slavery previously reviewed, it can be argued that the double chain around Gambino's neck represents slavery and the golden accessories that are often associated with a rapper's stereotype.

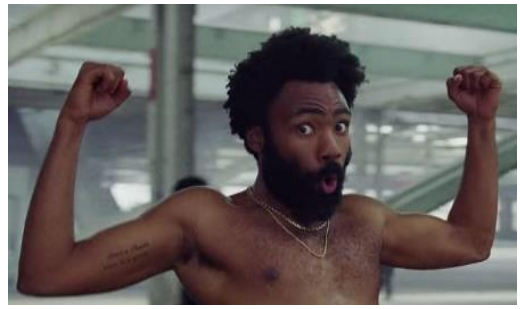

Image 10. Double chain around Gambino's neck (Source: Childish Gambino’s “This is America”)

The presence of old cars might be a referent to the lack of progress concerning the situation of African Americans in the United States, an issue that was addressed as well in the discussion regarding their portrayal in mass media.

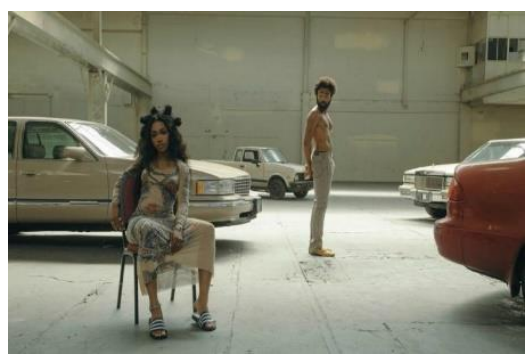

Image 11. Old cars featured in the music video (Source: Childish Gambino's “This is America”)

\subsubsection{Salience}

The relevant aspects regarding the salience are the cultural symbols, the focus, the foreground, and the overlapping. Throughout this analysis, the cultural symbols present in the video have been addressed. They play an important role to convey the criticism that Gambino intends concerning the perceptions of African Americans.

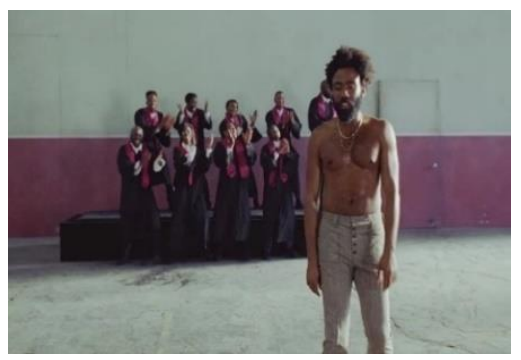

Image 12. Singing choir feature in the video (Source: Childish Gambino's "This is America”) 
The focus of the viewer is always challenged by the overlapping elements that the video offers. However, this is also an important connotation in the video. Beyond Gambino's actions in the video, it can be stated that it is precisely behind the singer's choreography and overall presence where key situations take place mostly regarding violence and chaos and death.

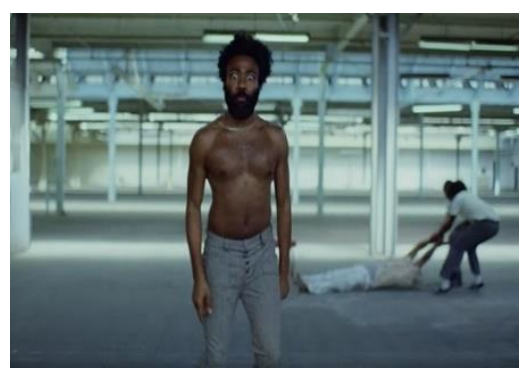

Image 13. Dead body being dragged (Source: Childish Gambino's “This is America”)

Gambino is the only character throughout the entire video who is shirtless. This is probably the most important aspect which can be analyzed thought salience. Following the movements of Gambino, the spectator is meant to split the attention between what really matters, and he is surrounded with, in the same way, that the choreography plays with the social distance, an aspect that has been discussed.

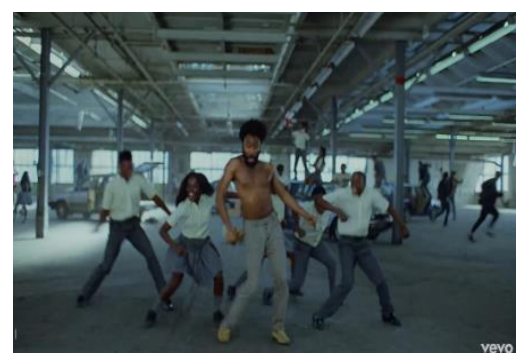

Image 14. Chaos behind Gambino's presence (Source: Childish Gambino’s “This is America”)

Combine with the lyrics, the music video of "This is America" presents an interesting criticism to the representation of African Americans in the United States. Gambino seems to coincide with different aspects of the literature that state how there are particular elements of the African American culture that are embraced and celebrated, while others are not only rejected but used to portray a negative image. Gambino plays with both views in order to convey a strong message through music that includes historical key elements, violence, and the manipulation of mass media.

\section{Conclusion}

I have offered a multimodal discourse analysis of Childish Gambino's video "This is America”. Using Machin (2010) Visual Semiotic Analysis and Halliday's FSL (1978), I have explored the most important elements that Gambino uses in order to offer a social critique concerned with the current situation and portrayal of African Americans and the issue of gun violence in the United States. Wilson (1973) defines racism as "an ideology of racial domination or exploitation that (1) incorporates beliefs in a particular race's cultural and/or inherent biological inferiority, and (2) uses such beliefs to justify and prescribe inferior or unequal treatment for that group" (as cited in Gravois \& Hunt, 1995: 48). However, it seems that regardless of the idealized multicultural society that the United States tries to sell, it could be stated that there are still concerning aspects in the United States, not only regarding African Americans but many minority groups. With the presence of mass media and now social media, these matters have only 
been accentuated, which in turn indicates that the obstacle of racism has never been overcome, but only evolved into what Littlefield (2008) calls "new racism". The views of Gambino about the perpetuated stereotypes that mass media shares are only an example of the partial or misleading trues that are manipulated by a few and presented to millions. The discourse that mass media and social media uses represents a useful but sharp tool, which can both benefit or wound a society; hence individuals should oppose ideas that are based on hatred or racism by being critical of what they are presented, and what they are consuming as spectators.

\section{Acknowledgements}

I would like to mention the support and advise from my professors Dr. Troy Crawford and Dr. Pierre-Luc Paquet.

This research did receive any specific grant from funding agencies in the public, commercial, or not-for-profit sectors.

Conflicts of interest: none

\section{References}

Bristor, J. M., Gravois, R., \& Hunt, M. R. (1995). Race and ideology: African-American images in television advertising. Journal of Public Policy \& Marketing, 14(1), 48-59.

Brown, T. L., \& Kopano, B. N. (Eds). (2014). Soul thieves. The appropriation and misrepresentation of African American popular culture. New York: Palgrave Macmillan.

Cartier, N. (2014). Black women on-screen as future texts: a new look at black pop culture representations. Cinema Journal, 53(4), 150-157. http://go.galegroup.com/ps/i.do?p=AONE\&u=pu\&id=GALE|A376509648\&v=2.1\&it=r\&sid= summon.

Chan, S. (2013) Using videos and multimodal discourse analysis to study how students learn a trade. International Journal of Training Research, 11(1), 69-78. https://doi.org/10.5172/ijtr.2013.11.1.69

Dixon, T. L. \& Linz, D. (2000). Overrepresentation and underrepresentation of African Americans and Latinos as Lawbreakers on television news. Journal of Communication, 5O(2), 131-154. https://doi.org/10.1111/j.1460-2466.2000.tb02845.x

Eyerman, R. (2001). Cultural trauma: Slavery and the formation of African American Identity. Cambridge: Cambridge University Press.

Fujioka, Y. (2005) Black Media Images as a Perceived Threat to African American Ethnic Identity: Coping Responses, Perceived Public Perception, and Attitudes Towards Affirmative Action. Journal of Broadcasting \& Electronic Media, 49(4), 450-467. https://doi.org/10.1207/s15506878jobem4904 6

Ghandnoosh, N. (2010). 'Cross-cultural' practices: interpreting non-African-American participation in hip-hop dance. Ethnic and Racial Studies, 33(9), 1580-1599. https://doi.org/10.1080/01419870903548799

Halliday, M. A. K. (1985). An introduction to functional grammar. London: Arnold.

Haratyan, F. (2011). Halliday's SFL and social meaning. In: 2nd International Conference on Humanities, Historical and Social Sciences 17, 260-264. https://pdfs.semanticscholar.org/834f/a499be33fd49e93192f1f4bb845c6becdfgc.pdf. 
Littlefield, M. (2008). The media as a system of racialization: Exploring images of African American woman and the new racism. American Behavioral Scientist, 51(5), 675-685. https://doi.org/10.1177/0002764207307747

Machin, D. (2010). Analyising popular music: Image, sound, text. London: Sage Publications.

Morgan, M. (1998). More than a mood or an attitude: Discourse and verbal genres in African-American culture. In S. S. Mufwene, J.R. Rickford, G. Bailey, \& J. Baugh (Eds.), African-American English: Structure, history and use (pp. 251-280). London: Routledge.

Morgan, M. (2002). Language, discourse and power in African American Culture. Cambridge: Cambridge University Press.

O'Halloran, K. L. (2011). Multimodal discourse analysis. In: K. Hyland \& B. Paltridge, (Eds.), The continuum companion to discourse analysis (pp. 120-136). London: Continuum International Publishing Group.

Punyanunt-Carter, N. M. (2008). The perceived realism of African American portrayals on television. The Howard Journal of Communications, 19, 241-257. https://doi.org/10.1080/10646170802218263

Van Leeuwen, T. (2015). Critical discourse analysis. The International Encyclopedia of Language and Social Interaction. https://doi.org/10.1002/9781118611463/wbielsi174

Wang, J. (2010). A critical discourse analysis of Barack Obama's speeches. Journal of Language Teaching and Research, 1(2), 254-261. doi 10.4304/jltr.1.3.254-261

Wodak, R. (2001). What CDA is about- a summary of its history, important concepts and its developments. In: R. Wodak \& M. Meyer (Eds.), Methods of critical discourse analysis (pp. 1-13). London: Sage Publications. 